\title{
Intradiscal Electrothermal Annuloplasty: CurRent ConCepts
}

\author{
Richard Derby, MD
}

Intradiscal electrothermal annuloplasty (IDET) is a minimally-invasive procedure for managing chronic discogenic LBP in patients failing conservative treatment and who may otherwise be candidates for spinal fusion. $(1,2)$ The concept of heating the disk may be attributed to M. E. Sluijter(3), who utilized a standard radiofrequency needle inserted into the center of the disc (4). Modern methods utilize a resistive thermal coil threaded about the circumference of the annulus (Oratec SpineCath) or an ionic heating catheter threaded across the posterior annulus (Tyco-Radionics discTrode)(5).

\section{OUtCOMES}

Initial results by Derby et al(6) and Saal et al(7) afforded positive response rates of $73 \%$ and $80 \%$, respectively. Subsequent studies(8-10) showed average decreases in visual analog scale (VAS) scores of $62.5-72 \%$, with decreases in SF36 body pain of 59-78\%. In contrast, recent studies report modest or poor outcomes $(11,12)$. Freeman et al $(11)$ found no significant benefit based upon their strict criteria for successful outcomes: no post-IDET neurological deficit, Low Back Outcome Score improvement $>7$ points, and improved SF-36 subsets. More recently, Pauza et al(12). showed significant improvement (VAS 2.4 vs 1.1 in IDET and control, respectively) in a double-blind placebo-controlled trial. Pauza et al, navigated the catheter to include the lateral and posterior annulus on both disc sides. Bilateral catheter insertions were performed when needed to completely cover the outer annulus. Derby et al (8) reported bet-

From Spinal Diagnostics and Treatment Center, Daly City, CA. Address Correspondence: Richard Derby, MD, 901 Campus Drive, Suite 310, Daly City, CA 94015. Email: rderby@spinaldiagnostics.com Funding: No external support was received in completion of this study. ter outcomes in patients with low-pressure-sensitive discs during discography. Pauza et al (12) did not confirm these results. Derby et al reported that $1 / 3$ of patients were significantly better, $1 / 3$ slightly or questionably better, and $1 / 3$ the same or worse. Requiring limited annular disruption and/or intact annuli, although potentially eliminating candidates, may improve outcomes. The best outcomes have been reported by Karasek and Bogduk andsubsequently by Mauer $(13,14)$, but only Karasek has passed the scrutiny of the peer review process. Two aspects of their studies that may have resulted in improved results are that Karasek required $\leq$ 2 quadrant disruption and Mauer required intact outer annuli.

One could postulate that good results can be attained with IDET when low back pain originates from growth of nocioceptive fibers into inner annular layers. Invoking this reasoning would lead to the expectation that no significant benefit would be realized when the low back pain resulted from high mechanical endplate loads (15). Individuals with pain precipitated by this last mechanism may account for the modest outcomes following IDET despite stringent inclusion criteria, since it is difficult to identify this subset of patients with low back pain. It is unclear if novel probe designs will improve outcomes. A multicenter study is in progress to examine this possibility. We predict results similar to those of the multicenter prospective IDET trial. Limitations of equipment and techniques do not guarantee precise determination of pain sources, which may contribute to modest outcomes.

An important question that must be answered is: what is the chance of a negative outcome following IDET? Given the alternatives of spinal fusion or doing nothing, patients generally will pursue an intervention that has minimal down- side risks if the chance of becoming worse is small. Although preliminary 6 month data did not report the percentage of patients with improved pain, $6 \%$ of IDET subjects reported worsened pain compared with $30 \%$ of control subjects. In studies reporting poorer outcomes (vide supra), approximately $30 \%$ of patients reported worsened pain. Using Pauza's criteria, the percentage of patients reporting worsened pain drops to $20 \%$. These data suggest that the probability of post-IDET worsening of pain may be no greater than that of patients choosing not to undergo the procedure, and in fact may be $6-20 \%$.

Wetzel et al (16) reported 2.4 mean VAS improvement and $56.2 \%$ of patients with "as much or somewhat better" pain (16). Forty-eight percent of patients reported $>50 \%$ pain relief at 6 months. Although double-blind randomized controlled studies showed modest outcomes, strict inclusion criteria, eg, disc height decrease $<30 \%$ without obesity, could afford $\sim 2.5$ mean VAS improvement with "as much or somewhat better pain" in $>50 \%$ of patients (17). Spinal fusion was performed in $<5 \%$ of patients treated with IDET. Some patients require spinal surgery 6-18 months after the procedure (18).

\section{MeChanism}

Proposed mechanisms include alteration of spinal segment mechanics via collagen modification, thermal nociceptive fiber destruction, biochemical mediation of inflammation(7), stimulation of an outer annular healing response, cauterization of vascular ingrowth and induced healing of annular tears(19). Shah et al(19). reported denaturation, shrinkage, coalescence of annular collagen and stromal disorganization following IDET in a cadaver model. However, other data suggest that collagen modification may not be not a primary effect $(20,21)$. While 
temperatures sufficient to coagulate nocioceptors may be achieved, temperatures sufficient to cause collagen contraction more than several millimeters beyond the catheter center have not been shown. Closure of annular fissures is possible, but has not been demonstrated experimentally. Physicians performing post-IDET discograms generally concede that radial tears remain; as a result it is unlikely that current protocols close fissures or improve disc stability. On the other hand, it is unlikely that heating causes destabilization, and may help seal or promote healing of the outer annular rim.

Therapeutic efficacy of intradiscal heating probably depends on transfer of heat through the nucleus, annulus or both. Bono(22) showed that a zone of potential denervation occurred at distances 12-14 $\mathrm{mm}$ from the catheter, with temperatures of $42{ }^{\circ} \mathrm{C}$ achieved at distances $<14 \mathrm{~mm}$. Wright(23) measured mean outer annular temperatures of $43.9 \pm 2.3{ }^{\circ} \mathrm{C}$ and concluded that these temperatures may coagulate nocioceptors. Typical procedures generate sufficient heat to ablate nerves (20). The Radionics Disc TRODE (IDRT) passes the active element across the outer posterior annulus, permitting outer annular temperatures of $45-50^{\circ} \mathrm{C}$ within minutes using radiofrequency-generated heat of $\sim 70{ }^{\circ} \mathrm{C}$. An in vivo histologic study (24) after failed IDET showed stromal disorganization, paucity of chondrocytes, and chondrocyte degeneration which may alter mechanical properties. These data support use of short catheters, which may prevent undesired tissue changes, especially at anterior disc.

RISK

The IDET procedure is relatively benign, but involves risks beyond needle penetration of the disc. Penetrating the posterior annulus, the catheter lies close to the dura and spinal roots. The catheter may navigate into a posterior disc protrusion and be seen posterior to the vertebral margin. Caution should be exercised if the catheter can not be advanced to a more ventral position. High temperatures in the epidural space may result when the catheter lies within a few millimeters of the traversing or exiting nerve root. Prolonged temperatures $>40^{\circ} \mathrm{C}$ may induce leg pain. Heat injury of the endplate is possible, although the risk is significantly less than that of laser therapy. Cadaver studies have not demonstrated significantly elevated endplate temperatures (25). It is difficult to determine the proximity of the catheter to the endplates with fluoroscopy. Cohen et $\mathrm{al}(17)$ found the only risk factor of IDET was obesity, which decrease success rates.

\section{SUMMARY}

IDET is a minimally-invasive procedure with low incidence of complications for the treatment of chronic discogenic LBP. Although the mechanism is unclear, benefits putatively result from thermal nociceptor ablation. While studies have shown modest outcomes, strict inclusion criteria, such as $<30 \%$ disc height decrease without obesity, may afford $\sim 2.5$ mean VAS improvement with "as much or somewhat better" pain in $>50 \%$ of patients. Studies examining pain sources, criteria, and comparing IDET with other treatments are needed. Although challenges remain to improve therapeutic efficacy, IDET is less invasive than open surgery and avoids associated complications. Careful patient selection and proper technique improve outcomes.

\section{Author Affiliation: \\ Richard Derby, MD \\ Associate Clinical Professor \\ Department of Orthopedic Surgery \\ Stanford University \\ Spinal Diagnostics and Treatment \\ Center \\ 901 Campus Drive, Suite 310 \\ Daly City, CA 94015 \\ E-mail: rderby@spinaldiagnostics.com}

\section{RefERENCES}

1. Djurasovic M, Glassman SD, Dimar JR et al. Vertebral osteonecrosis associated with the use of intradiscal electrothermal therapy: a case report. Spine 2002;27:E325328.

2. Heary RF. Intradiscal electrothermal annuloplasty: the idet procedure. J Spinal Disord 2001;14:353-360.

3. Sluijter ME. The use of radiofrequency lesions for pain relief in failed back patients. Int Disabil Stud 1988;10:37-43.

4. VanKleef M, Barendse G, Wilmink J et al. Percutaneous intradiscal radiofrequency thermocoagulation in chronic non-specific low back pain. The Pain Clinic 1996;9:259268.

5. Derby R, Eek B, Ryan D. Intradiscal electrothermal annuloplasty. Scientific Newsletter of the International Spinal Injection Society 1998;3.

6. Derby R. Intradiscal Electrothermal Annu loplasty. Paper presented at: North American Spine Society 13th Annual Meeting,
Oct 28-31, 1998; San Francisco, CA.

7. Saal JS, Saal JA. Management of chronic discogenic low back pain with a thermal intradiscal catheter. A preliminary report. Spine 2000;25:382-388.

8. Derby R EB, Chen Y, O' Neill C et al. Intradiscal Electrothermal Annuloplasty: A Novel Approach for Treating Chronic Discogenic Back Pain. Neuromodulation 2000;3:8288.

9. Saal JA, Saal JS. Intradiscal electrothermal treatment for chronic discogenic low back pain: a prospective outcome study with minimum 1-year follow-up. Spine 2000;25: 2622-2627.

10. Saal JA, Saal JS. Intradiscal electrothermal treatment for chronic discogenic low back pain: prospective outcome study with a minimum 2-year follow-up. Spine 2002;27:966-973; discussion 973-964.

11. Freeman $B$, Fraser $\mathrm{R}$, Cain $\mathrm{C}$ et al. A randomized, double-blind controlled efficacy study: Intradiscal electrothermal therapy (IDET) versus placebo. Paper presented at: International Society for the Study of the Lumbar Spine, 3oth annual meeting, Vancouver, Canada, May 13-17, 2003.

12. Pauza K, Howell S, Dreyfuss P et al. A randomized, double-blind, placebo controlled trial evaluating the efficacy of intradiscal electrothermal anuloplasty for the treatment of chronic discogenic low back pain: 6-month outcomes. Paper presented at: International Spinal Injectinon Society, 1oth annual scientific meeting, Austin, TX, September 7, 2002.

13. Karasek M, Bogduk N. Twelve-month follow-up of a controlled trial of intradiscal thermal anuloplasty for back pain due to internal disc disruption. Spine 2000;25: 2601-2607.

14. Maurer P, Squilante D, Dawson K. Is IDET effect treatment for discogenic low back pain? A prospective cohort outcome study (1-2 year follow-up) identifying successful patient selection criteria. Paper presented at: International Spinal Injection Society 10 th annual scientific meeting, Austin, TX September 7, 2002.

15. Adams MA, Dolan P, Hutton WC. Diurnal variations in the stresses on the lumbar spine. Spine 1987;12:130-137.

16. Wetzel FT, McNally TA, Phillips FM. In tradiscal electrothermal therapy used to manage chronic discogenic low back pain: new directions and interventions. Spine 2002;27:2621-2626.

17. Cohen SP, Larkin T, Abdi S et al. Risk factors for failure and complications of intradiscal electrothermal therapy: a pilot study. Spine 2003;28:1142-1147.

18. Lagattuta FB, Brady R, Hudoba $P$ et al. Incidence of intervertebral fusion in patients treated with intradiscal electrothermotherapy. Paper presented at: American Association of Orthopedic Medicine Annual Meeting, May 4-6, 2000; Amelia Island, FL.

19. Shah RV, Lutz GE, Lee J et al. Intradis 
kal electrothermal therapy: a preliminary histologic study. Arch Phys Med Rehabil 2001;82:1230-1237.

20. Kleinstueck F, Diederich C, Nau W et al. The IDET Procedure: Temperature Distributions and Biomechanical Effects on Human Lumber Disc. Paper presented at: 15th Annual Meeting of the North American Spine Society, 2000; New Orleans, LA

21. Lee J, Lutz GE, Campbell D et al. Stability of the lumbar spine after intradiscal electrothermal therapy. Arch Phys Med Reha- bil 2001;82:120-122.

22. Bono C, Garfin S, Iki K et al. Temperatures within the lumbar disc and endplates during intradiscal electrothermal therapy: Formulation of a predictive temperature map in relation to distance from the catheter. Paper presented at: ISIS 10th Annual scientific meeting, 2002; Austin, TX.

23. Wright RE. Precise in Vivo Measurement of Peak Intra-Annular Temperatures Obtained During Intradiscal Electrothermal Therapy. Paper presented at: 13th annual meeting IITS, Williamsburg, VA, June 8-10,
2000.

24. Ahuja S, Maury A, Gibbs A et al. In-vivo histological changes in discs following failed intra-discal eletrothemal therapy. Paper presented at: BritSpine 2002; 27 February - 1 March, 2002, 2002; Birmingham, UK.

25. Yetkinler DN, Nau WH, Brandt LL. Disc temperature measurements during nucleoplasty and IDET procedures. Paper presented at: 6th International Congress on Spinal Surgery, September 4-7, 2002; Ankara, Turkey. 
